\title{
Acute left varicocele in an adult
}

\author{
Miguel Angel Arrabal-Polo MD PhD, Sergio Merino-Salas MD
}

See also the practice article by Forster and Biyani on page 321 and at www.cmaj.ca/lookup/doi/10.1503/cmaj.121445

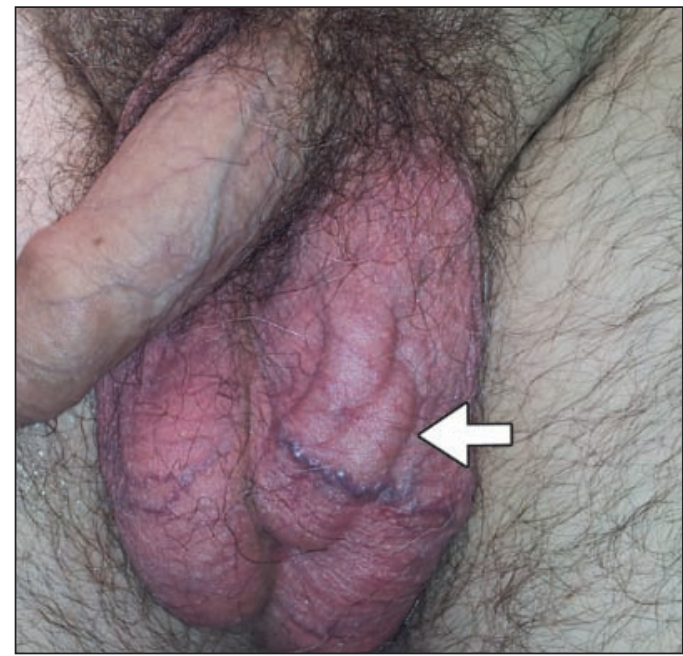

Figure 1: Left-sided varicocele (arrow) that developed suddenly in a 52-year-old man.

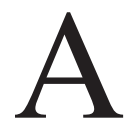
52-year-old man with a history of hypertension was referred because varicose veins had developed in his scrotum 2 weeks earlier. During examination of his genitals, an enlarged varicose vein was observed along the left spermatic cord (Figure 1). An abdominal mass was found by deep abdominal palpation. Abdominopelvic computed tomography was performed, and a tumour was seen in the left kidney (Figure 2). We postulated that this tumour was the cause of the left varicocele. Open radical nephrectomy of the left kidney was performed and confirmed the diagnosis of renal cell carcinoma. Minutes after nephrectomy, the left varicocele disappeared.

A varicocele is a dilation of the pampiniform plexus of the spermatic cord; this network of veins is dependent on the spermatic vein. Varicoceles develop as a result of venous reflux in the presence of increased venous pressure or defective venous valves. Varicoceles occur on the left side in most cases because of the relation of the

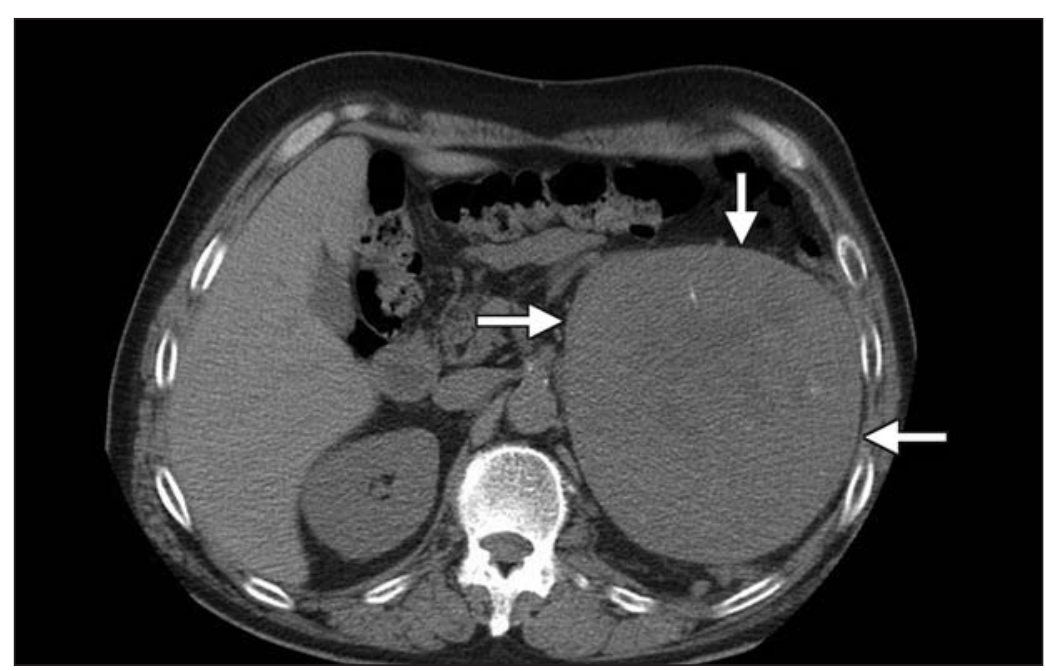

Figure 2: Abdominal computed tomographic scan showing a large tumour (arrows) in the left kidney.

spermatic vein to the left renal vein (the spermatic vein opens at a sharp angle into the left renal vein). ${ }^{\prime}$ On the right side, the spermatic vein opens into the much larger inferior vena cava. The presence of an isolated right varicocele may indicate the presence of a tumour that compresses venous return in the inferior vena cava. $^{1,2}$

Although left varicoceles usually occur physiologically, when one develops acutely in a man with no history of previous genital trauma, this raises suspicion of a retroperitoneal mass (usually renal cancer). In this situation, a thorough physical examination, further imaging and referral to a urologist may be indicated. ${ }^{3}$

\section{References}

1. Stahl P, Schlegel PN. Standardization and documentation of varicocele evaluation. Curr Opin Urol 2011;21:500-5.

2. El-Saeity NS, Sidhu PS. "Scrotal varicocele, exclude a renal tumour." Is this evidence based? Clin Radiol 2006;61:593-9.

3. Ljungberg B, Cowan N, Hanbury DC. Guidelines on renal cell carcinoma. Arnhem (the Netherlands): European Association of Urology; 2010.
Competing interests: None declared.

Affiliation: From the

Department of Urology, San Cecilio University Hospital, Granada, Spain

This article has been peer reviewed.

Correspondence to:

Miguel Angel Arrabal-Polo, arrabalp@ono.com

CMAJ 2013. DOI:10.1503 /cmaj.121253 